\title{
Temperature Stabilisation in Fischer-Tropsch Reactors Using Phase Change Material (PCM)
}

\author{
Ademola O. ODUNSI ${ }^{1, *}$, Tadhg S. O’DONOVAN ${ }^{2}$, David A. REAY ${ }^{3}$ \\ * Corresponding author: Tel.:+44 (0)1314514718; Email: aoo39@hw.ac.uk \\ 1, 2, 3 Institute of Mechanical Process and Energy Engineering, Heriot-Watt University, UK
}

\begin{abstract}
The Fischer-Tropsch (FT) reaction is a highly exothermic reaction. The high exothermicity combined with a high sensitivity of product selectivity to temperature, constitute the main challenges in the design of FT reactors. The use of micro-encapsulated- Phase Change Material (PCM) in conjunction with the supervisory temperature control mechanism has been suggested as an effective way of mitigating these challenges. A 2-dimensional, pseudo-homogeneous, steady-state model, with the dissipation of the enthalpy of reaction into an isothermal PCM sink, in a fixed bed reactor is presented. Effective temperature control with the PCM shows a shift in thermodynamic equilibrium favouring the selectivity of $\mathrm{C} 5$ to the disadvantage of $\mathrm{CH}_{4}$ selectivity - a much desired outcome in the hydrocarbon Gas-to-Liquid industry.
\end{abstract}

Keywords: Phase change material (PCM), Fischer-Tropsch, Exothermic reaction, Temperature

\section{Introduction}

The Fischer-Tropsch Synthesis (FTS) entails the chemical conversion of syngas to synthetic, liquid hydrocarbon fuels (e.g. diesel, petrol and linear $\alpha$-olefins) as a result of an aggregate of surface polymerisation reactions occurring in situ, on active sites of catalysts (Co, Ni, Fe and $\mathrm{Ru})$. The availability of a wide variety of feedstock, increasing requirement for cheaper and sustainable sources of energy, and the need to monetize smaller and/or stranded pockets of natural resources (through the use of smaller and more compact reactors) altogether have lent momentum to the process in recent times [1-6]. In fact, it has been estimated that by 2015 , the global annual production rate of liquid fuels and chemicals from the FTS would be approximately 30 million tonnes [1].

The FT reaction is strongly exothermic, with enthalpy of reaction of between -152 and $-167 \mathrm{~kJ} / \mathrm{mole}$ and the adiabatic temperature rise, $\left(T_{a d}=\Delta_{R} H / C_{p}\right)$ of up to $1750 \mathrm{~K}$. It is thus crucial to ensure that the FT reactor has a welldesigned heat rejection method $[3,6]$. This requirement for excellent heat rejection has inspired the wide variety of FT reactor designs available on the market today such as: the fluidised bed (circulating and fixed), slurry phase, and fixed bed reactors (FBR), etc. [3,913]. The FTS is broadly classified into two categories namely: the Low Temperature Fischer-Tropsch (LTFT) at $200-250^{\circ} \mathrm{C}$, and the High Temperature Fischer-Tropsch (HTFT) at $300-350^{\circ} \mathrm{C}[1-3,5,6,9-13]$.

The main equation of reaction of the FTS may be represented as follows:

$\mathrm{CO}+2 \mathrm{H}_{2} \rightarrow\left(-\mathrm{CH}_{2-}\right)+\mathrm{H}_{2} \mathrm{O} \Delta_{\mathrm{R}} H_{298}^{\theta}=-152 \frac{\mathrm{kJ}}{\mathrm{mol}}$

For a full kinetic description of the process, the methane synthesis is considered as a separate reaction [1-3]:

$\mathrm{CO}+3 \mathrm{H}_{2} \rightarrow \mathrm{CH}_{4}+\mathrm{H}_{2} \mathrm{O} \Delta_{\mathrm{R}} H_{298}^{\theta}=-206 \frac{\mathrm{kJ}}{\mathrm{mol}}$

Lastly, on a Fe-based catalyst, the undesirable water-gas shift reaction, producing $\mathrm{CO}_{2}$ as a diluent, plays an important role:

$\mathrm{CO}+\mathrm{H}_{2} \mathrm{O} \rightarrow \mathrm{CO}_{2}+\mathrm{H}_{2} \Delta_{\mathrm{R}} H_{298}^{\theta}=-41 \frac{\mathrm{kJ}}{\mathrm{mol}}$

\subsection{Objectives}


The objective of this paper is to present a 2dimensional pseudo-homogeneous, steadystate model of a Fe-catalysed LTFT FBR with temperature modulation using the combined effect of the PCM and jacket cooling liquid. To the best of our knowledge, this has not been previously done in open literature. The effects of varying inlet/cooling jacket temperature, on productivity, conversion, etc. will also be examined and discussed.

\subsection{Fixed Bed Reactor (FBR)}

The FBR is basically a shell and tube heat exchanger. The tubes are packed with catalyst and act as the site of the reaction. The heat from the reaction is removed by surrounding cooling, saturated water. It is assumed the water is circulated at a rate high enough as to maintain the outer tube wall at constant temperature $[3,7]$. The FBR has been selected for this study principally because it presents the greatest challenge in terms of heat rejection [5-11]. It is still used in industry (Shell and Sasol) because (i) it does away with the need for separating products from the catalyst, (ii) kinetic data from a single tube is quite representative at the pilot-plant scale and (iii) it features low fluid inventory [2, 5-12].

\subsection{Optimisation and Process Conditions}

Optimisation of the selectivity of the desired spectrum of products is central to the economics of the FTS. There is however a conflict between competing forces, including: the operating conditions (T, P, GHSV, etc.), the factors controlling them, catalyst properties and reactor structure. It is pertinent to note that increasing temperature affects the FTS adversely on all fronts (Table 1), including a shift towards high selectivity for lower carbon number products. The challenge of exothermicity and sensitivity of product selectivity has previously been tackled by: reducing the upper limit of the tube diameters, recycling the tail gas and liquid, reducing catalyst activity and/or average temperature, using high gas velocity to generate turbulent flow (with a trade-off of lower conversion of reactants) $[1-3,5,8-11]$.

Table 1: Influence of process conditions on the selectivity of FTS: $(+)=$ increase, $(-)=$ decrease and $(*)$ $=$ complex relationship $[3,5]$

\begin{tabular}{|l|c|c|c|c|}
\hline $\begin{array}{l}\text { Process } \\
\text { Condition }\end{array}$ & $\begin{array}{c}\mathbf{S}_{\mathbf{0}}: \mathbf{S}_{\mathbf{p}} \\
\text { ratio }\end{array}$ & $\begin{array}{l}\text { Carbon } \\
\text { deposition }\end{array}$ & $\mathbf{S}_{\mathbf{C H} 4}$ & $\boldsymbol{\alpha}$ \\
\hline $\begin{array}{l}\text { Increase } \\
\text { Temperature }\end{array}$ & - & + & + & - \\
\hline $\begin{array}{l}\text { Increase } \\
\text { Pressure }\end{array}$ & + & $*$ & $*$ & - \\
\hline $\begin{array}{l}\text { Increase } \\
\mathrm{H}_{2}: \text { CO ratio }\end{array}$ & - & - & - & + \\
\hline $\begin{array}{l}\text { Increase } \\
\text { Conversion }\end{array}$ & $*$ & - & + & + \\
\hline $\begin{array}{l}\text { Increase } \\
\text { GHSV }\end{array}$ & $*$ & + & $*$ & - \\
\hline
\end{tabular}

In order to maximise desired product selectivity and prevent potential thermal runaways, the reactor temperature needs to be maintained within a narrow optimum range under operating conditions. This must be done however, without over-cooling the reactor such that the reaction is extinguished altogether. Carefully selected PCMs could potentially help to achieve this delicate balance.

\section{Phase Change Material (PCM)}

Phase change materials (PCM) have found application in the cooling of micro-electronics, thermal energy storage (TES) and temperature stabilisation in modern buildings. With modifications, they may also be used in chemical reactors. Proportional-integraldifferential (PID) units used for supervisory temperature control in reactors may be limited by the size and location of thermocouples within the reactor. This is especially true for heterogeneous reactions like the FTS, where chemical reactions occur on active catalyst sites [4, 13-14]. Micro-encapsulated PCM, with a phase transition temperature (ptt) lying between a nominal operating temperature and the onset temperature of carbon deposition or catalyst de-activation (whichever occurs first) can act as a rapid-responding, distributed temperature controller [4, 13-14]. In the simulation presented in this paper, tin $(\mathrm{ptt}=$ $232^{\circ} \mathrm{C}$ ) is the $\mathrm{PCM}$ used for temperature 
stabilisation in the LTFT.

\subsection{PCM in FTS FBR}

The use of PCM in conjunction with traditional cooling systems can be a very effective method of heat rejection for the FTS reactor. Dissipating heat into PCM results in a nearly isothermal heat sink. This has huge potential for keeping the propensity of the FBR for parametric sensitivity and vacillation between multiple steady states in check. This is because through its isothermal phase transition (fusion and melting) cycles, the PCM acts as a thermal flywheel mitigating temperature excursions on the one hand while preventing reaction extinction on the other $[4,13]$.

Unlike in TES, bulk PCM is not very useful in reactors because of non-uniform heat transfer. For PCM to find relevance in a FBR, it should be: (1) sufficiently small to ensure rapid melting (order of micro-seconds). It has been shown that a small reduction in the characteristic length of the PCM can have an exponential reduction in the melting time of the PCM, (2) encapsulated in an inert shell (e.g. $\mathrm{SiO}_{2}$ ), in order to avoid agglomeration, leakage or contamination, (3) should form a homogeneous mixture with reactants or catalyst in order to quench local micro-sized hotspots [14-15].

\section{FTS FBR Model with PCM}

The most comprehensive method of modelling the FTS reactor is the 2-dimensional heterogeneous approach. Usually, there are no reliable data or correlations to carry out the modelling exercise [3, 18-21]. The next best and widely accepted method is the 2-D pseudo-homogeneous approach which treats the fluid and catalyst as one continuous phase with effective parameters. The heat transfer within the bed to the reactor wall is represented by an effective radial conductivity and heat transfer coefficient. This model also accounts for axial mixing and transport limiting properties such as pore diffusion, particle tortuosity, etc. [1-3,18-21]. This is the model adopted in this paper. Other less accurate methods in literature, neglecting transport parameters and radial gradients, include the 1-D models [1-3,18-21].

The kinetic and operating conditions data used for this simulation (Table 2) were obtained from Jess and Kern [1].The rate equations for reactions (1)-(3) above were determined by systematic experiments using commercial Fe catalyst in its original form and the following equations were derived for $\mathrm{T}>220^{\circ} \mathrm{C}$ and particle diameter $3 \mathrm{~mm}\left(V_{p} / A_{p, e x}=0.5 \mathrm{~mm}\right)[1]$ :

$$
\begin{gathered}
r_{m, H_{2}, F T}=-\frac{d \dot{n}_{H_{2}}}{d m_{c a t}}=\frac{k_{m, H_{2} \text { eff }, F T}}{1+1.6 \frac{c_{H_{2} O}}{c_{C O}}} c_{H_{2}, g} \\
k_{m, H_{2} \text { eff }, F T}=5.1 \frac{m^{3}}{k g . s} e^{\frac{-52000}{R T}} \\
r_{m, H_{2}, M}=-\frac{d \dot{n}_{H_{2}}}{d m_{c a t}}=k_{m, H 2, e f f, M} c_{H_{2, g}} \\
k_{m, H 2 e f f, F T}=27.3 \frac{\mathrm{m}^{3}}{\mathrm{~kg} . \mathrm{s}} e^{\frac{-70000}{R T}} \\
r_{m, H_{2}, W G S}=-\frac{d \dot{n}_{H_{2}}}{d m_{c a t}}=k_{m, H_{2}, \text { eff }, M} c_{H_{2} O, g} \\
k_{m, H_{2} \text { eff }, F T}=155 \frac{\mathrm{m}^{3}}{\mathrm{~kg} . \mathrm{s}} e^{\frac{-70000}{R T}}
\end{gathered}
$$

The material, energy and momentum (Ergun's equation for packed beds) balances and their respective boundary conditions are as set out respectively follows:

$$
\begin{aligned}
& \rho_{f} \cdot u_{s} \cdot \frac{\partial w_{j}^{f}}{\partial z}=-\rho_{f} \cdot w_{j} \cdot \frac{\partial u_{s}}{\partial z}-w_{j} \cdot u_{s} \cdot \frac{\partial \rho_{f}}{\partial z} \\
& +D_{e r} \cdot\left(\frac{\partial \rho_{f}}{\partial r} \cdot \frac{\partial w_{j}^{f}}{\partial r}+\frac{\rho_{f}}{r} \cdot \frac{\partial w_{j}^{f}}{\partial r}+\rho_{f} \cdot \frac{\partial^{2} w_{j}^{f}}{\partial r^{2}}\right)+r_{j} \cdot M_{j} \cdot \rho_{b}^{c a t}
\end{aligned}
$$




$$
\begin{aligned}
\rho_{f} \cdot u_{s} \cdot C_{p}^{f} \cdot \frac{\partial T^{f}}{\partial z}=\kappa_{e r} \cdot\left(\frac{1}{r} \cdot \frac{\partial T^{f}}{\partial r}\right. & \left.+\frac{\partial^{2} T^{f}}{\partial r}\right) \\
& -\rho_{b}^{c a t} \cdot \sum r_{i} \cdot\left(\Delta_{R} H_{i}\right)
\end{aligned}
$$

Whence,

$$
\begin{gathered}
\sum r_{i} \cdot\left(\Delta_{R} H_{i}\right)=r_{m, H 2, F T} \cdot\left(\Delta_{R} H_{F T}\right)+r_{m, H 2, M} \cdot\left(\Delta_{R} H_{M}\right) \\
+r_{m, H 2, W G S} \cdot\left(\Delta_{R} H_{W G S}\right)-r_{P C M} \cdot\left(\Delta_{f u s} H_{P C M}\right)
\end{gathered}
$$

$$
\left(\frac{\rho D_{p}}{G^{2}}\right) \cdot\left(\frac{\varepsilon^{3}}{1-\varepsilon}\right) \frac{d P}{d z}=150 \cdot \frac{(1-\varepsilon)}{\left(\frac{D_{p} \cdot G}{\mu}\right)}+1.75
$$

The steady state boundary conditions (at $\mathrm{t}>0$ ) are given below:

$$
\begin{aligned}
& \left.\frac{\partial w_{j}^{f}}{\partial r}\right|_{r=0}=0 \text { for all } \mathrm{z} \\
& \left.\frac{\partial w_{j}^{f}}{\partial r}\right|_{r=R}=0 \text { for all } \mathrm{z} \\
& T^{f}=T_{\text {cool }}=\left.T_{0}\right|_{z=0} \\
& \left.\frac{\partial T^{f}}{\partial r}\right|_{r=0}=0 \text { for all } \mathrm{z} \\
& -\kappa_{e r} \cdot \frac{d T^{f}}{d r}=\left.h_{w, \text { int }, 1} \cdot\left(T_{w, \text { int }, 1}-T_{w, \text { int }, 2}\right)\right|_{r=R} \\
& \dot{q}=h_{w, \text { int }}\left(T_{w, \text { int }, 1}-T_{w, \text { int }, 2}\right)=U_{\text {wall }}\left(T_{w, \text { int }, 2}-T_{\text {cool }}\right) \\
& \text { where: } U_{\text {wall }}=\left(\frac{d_{\text {wall }}}{\kappa_{\text {wall }}}+\frac{1}{h_{w, e x}}\right)^{-1} \\
& u_{s}=u_{s, f e e d} ; p=p_{\text {feed }} \text { for } \mathrm{z}=0
\end{aligned}
$$

The effect of axial mixing has been left out of the material (7) and energy balance (8) equations because the depth of the packed bed $(12 \mathrm{~m})$ is far in excess of 50 times the catalyst particle diameter $(3 \mathrm{~mm})[1,3,19-20]$. The
PCM parameters are outlined in Table 3 below. The "heat sink" effect of the PCM was reflected as the enthalpy of fusion in equations (8) and (8a). This is incorporated into the model through the so called "effective heat capacity method" $[16,17]$. In this method, the effective heat capacity of the melting PCM was adjusted to account for latent enthalpy of fusion. The effect of this is that the melting PCM has a much higher heat capacity than either the solid or liquid states. Therefore, during the heat transport process, the temperature of the melting material (and by extension, that of the reaction fluid/catalyst system) does not change appreciably, which is a realistic assumption. The effective heat capacity of the PCM at different temperature zones is given as:

$$
\begin{array}{rlrl} 
& C_{p(p c m) s} & T<T_{m} \\
C_{p(p c m)}= & C_{p(p c m) s}+\frac{\Delta f u s H}{\Delta T} & T_{m} \leq T \leq\left(T_{m}+\Delta T\right) \\
& C_{p(p c m) s} & T>\left(T_{m}+\Delta T\right)
\end{array}
$$

In addition to the $C_{p}$, the other temperature dependent properties of the PCM are the thermal conductivity, $\kappa_{P C M}$ and the density, $\rho_{P C M}$. If the fraction of the melt which is liquid is defined as $\varphi$, such that $0 \leq \varphi \leq 1$, the individual properties may be approximated by the linear expressions:

$$
\begin{aligned}
& \kappa_{P C M}(T)=\kappa_{\mathrm{PCM}, \mathrm{s}}(1-\varphi)+\kappa_{\mathrm{PCM}, 1} \times \varphi \\
& \rho_{P C M}(T)=\rho_{\mathrm{PCM}, \mathrm{s}}(1-\varphi)+\rho_{\mathrm{PCM}, 1} \times \varphi
\end{aligned}
$$

The homogeneous nature of the model is extended to include the properties of the PCM in the fluid-catalyst system by defining an arbitrary index $\omega$ (ratio of mass of PCM to mass of catalyst). The temperature dependent properties for the pseudo-homogeneous-fluidcatalyst-PCM-system can then be approximated as:

$$
\kappa_{f, c a t, P C M}=\frac{1}{(\omega+1)} \cdot \kappa_{f, c a t}+\frac{\omega}{(\omega+1)} \cdot \kappa_{P C M}(T)
$$




$$
\begin{aligned}
& \rho_{f, c a t, P C M}=\frac{1}{(\omega+1)} \cdot \rho_{f, c a t}+\frac{\omega}{(\omega+1)} \cdot \rho_{P C M}(T) \\
& C_{p_{f, c a t, P C M}}=\frac{1}{(\omega+1)} \cdot C_{p_{f, c a t}}+\frac{\omega}{(\omega+1)} \cdot C_{p_{P C M}}(T)
\end{aligned}
$$

An arbitrary value of 0.5 was chosen for $\omega$. Correlations of the physical parameters including constitutive equations are detailed in $[1,2]$. There are no interactions between the individual tubes of a FBR and there is no rotational effect considered, as such, it is sufficient and computationally cheaper to model a single tube as opposed to the whole reactor. Advantage was also taken of the tube's symmetry and a 2-D axisymmetric model was set up.

Table 2: FTS data at $513 \mathrm{~K}$ and $2400 \mathrm{kPa}$ used in modelling reactor [1]

\begin{tabular}{ll}
\hline Parameter & Value \\
\hline Superficial gas velocity, $u_{s}$ & $0.55 \mathrm{~ms}^{-1}$ \\
Diameter of catalyst particle, $D_{p}$ & $3 \mathrm{~mm}$ \\
Total molar gas concentration, $\rho_{\text {mol }}$ & $563 \mathrm{molm}^{-3}$ \\
Length of tubes & $12 \mathrm{~m}$ \\
Internal tube diameter & $12.8 \mathrm{~mm}$ \\
H2: CO ratio in syngas & 2 \\
Kinematic viscosity of feed gas, $v_{\text {gas }}$ & $4 \times 10^{-6} \mathrm{~m}^{2} \mathrm{~s}^{-1}$ \\
Thermal conductivity of gas mixture $\kappa_{\text {gas }}$ & $0.16 \mathrm{Wm}^{-1} \mathrm{~K}^{-1}$ \\
Effective radial thermal conductivity, $\kappa_{e r}$ & $6.3 \mathrm{Wm}^{-1} \mathrm{~K}^{-1}$ \\
Heat capacity of gas mixture, $C_{p, f, c a t}$ & $30 \mathrm{Jmol}^{-1} \mathrm{~K}^{-1}$ \\
Heat transfer coefficient (bed to internal & $900 \mathrm{Wm}^{-2} \mathrm{~K}^{-1}$ \\
tube wall), $h_{w, \text { int }}$ & \\
Thermal conductivity of wall material & $50 \mathrm{Wm}^{-1} \mathrm{~K}^{-1}$ \\
(steel), $\kappa_{w a l l}$ & \\
External heat transfer coefficient, $h_{w, e x}$ & $1600 \mathrm{Wm}^{-1} \mathrm{~K}^{-1}$ \\
Thermal transmittance, $U_{\text {wall }}$ & $1380 \mathrm{Wm}^{-1} \mathrm{~K}^{-1}$ \\
Bulk density of bed, $\rho_{b}$ & $790 \mathrm{kgm}^{-3}$ \\
\hline
\end{tabular}

Table 3: PCM and temperature dependent properties

\begin{tabular}{lll}
\hline Parameter & Value & Units \\
\hline PCM & $\mathrm{Sn}$ & - \\
Melting temperature & 505 & $\mathrm{~K}$ \\
Latent enthalpy of fusion & 60500 & $\mathrm{~J} / \mathrm{kg}$ \\
Density of solid & 7280 & $\mathrm{~kg} / \mathrm{m}^{3}$ \\
Density of liquid & 6940 & $\mathrm{~kg} / \mathrm{m}^{3}$ \\
Heat capacity of solid & 231 & $\mathrm{~J} /(\mathrm{kg} . \mathrm{K})$ \\
Heat capacity of liquid & 244 & $\mathrm{~J} /(\mathrm{kg} . \mathrm{K})$ \\
Thermal conductivity of solid & 73 & $\mathrm{~W} /(\mathrm{m} . \mathrm{K})$ \\
Thermal conductivity of liquid & 33.5 & $\mathrm{~W} /(\mathrm{m} . \mathrm{K})$ \\
Differential melting range, $\Delta \mathrm{T}$ & 2.0 & $\mathrm{~K}$ \\
\hline
\end{tabular}

\subsection{Results and Discussion}

The model was implemented using COMSOL Multi-physics 4.4. This application facilitated the interfacing of the process chemistry, heat transport and fluid flow in a packed bed.

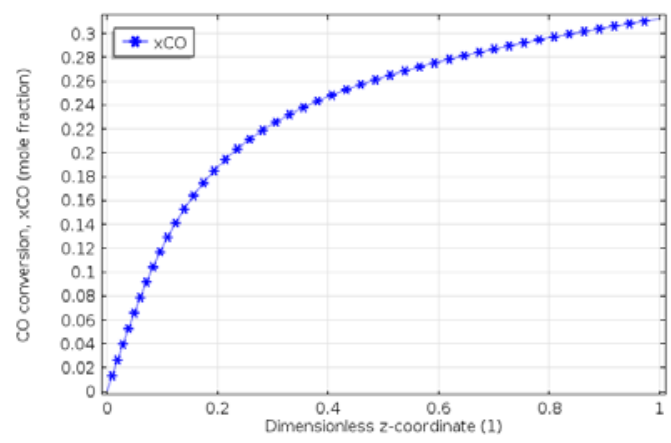

Figure 1: Conversion of $\mathrm{CO}, 240^{\circ} \mathrm{C}, 24 \mathrm{bar}$

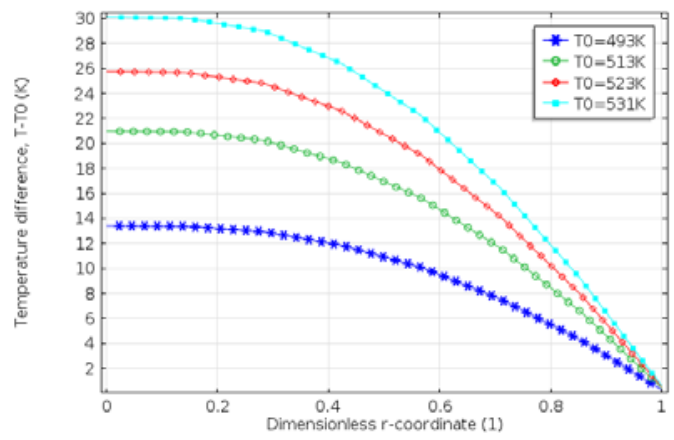

Figure 2: Radial temperature profile at hotspot

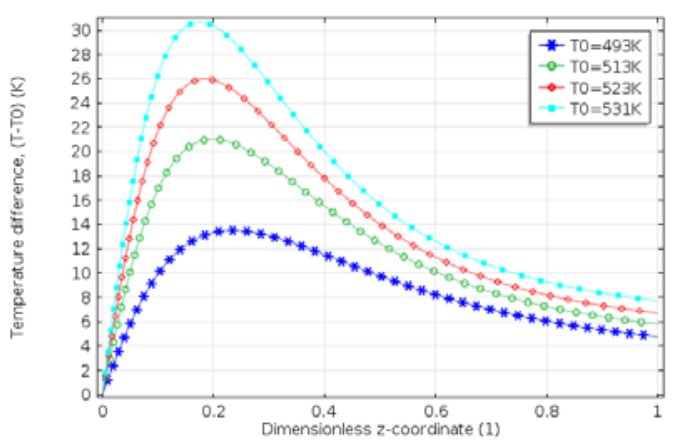

Figure 3: Axial temperature profiles at various T0

Due to the large aspect ratio, the mesh had to be rescaled in the radial direction. No significant changes were observed in the numerical results upon applying finer meshing settings. The conversion of CO (Figure 1) was $31 \%$ per pass at the base case temperature (i.e. inlet syngas temperature $=$ wall temperature) of $513 \mathrm{~K}$ which compares very- 


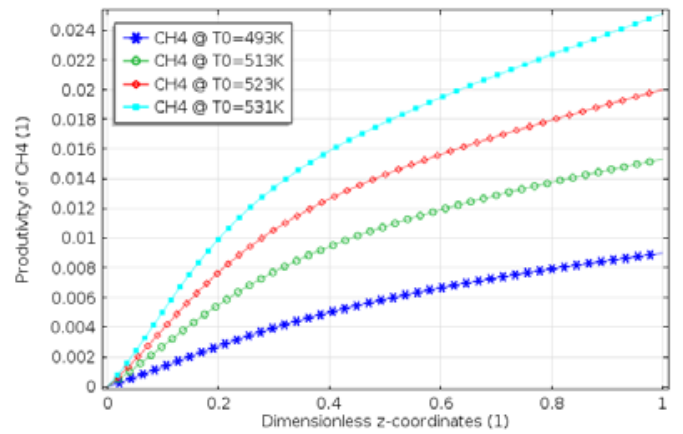

Figure 4: $\mathrm{CH} 4$ productivity at various T0

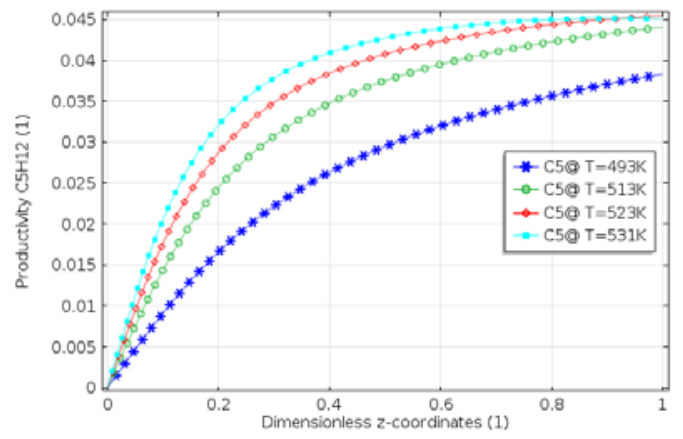

Figure 5: C5 productivity at various T0

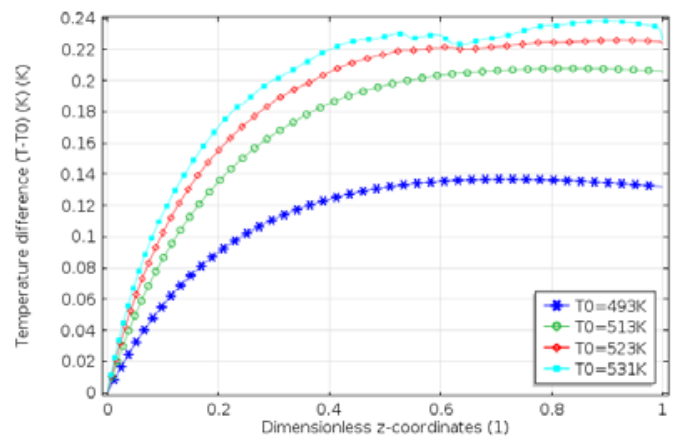

Figure 6: Axial temperature profile at various T0 with PCM-temperature- regulation $(\mathrm{w}=0.5)$

-well with $32 \%$ obtained by Jess and Kern [1].The selectivity to methane (based on $\mathrm{CO}$ ) was about $5 \%$ compared to $6 \%$ obtained in [1]. The radial and axial temperature profiles are depicted in Figures 2 and 3. The so-called hotspots or maximum temperature occur near the tube inlet at position $0.17 \quad(\mathrm{z}=2 \mathrm{~m})$ compared to $\mathrm{z}=1.5 \mathrm{~m}$ obtained in [1]. Based on these similarities, it was possible to carry out parametric studies, thus simulating fluctuations in process conditions.

\subsection{Effect of Inlet/Wall Temperature}

The inlet temperature of the syngas and the

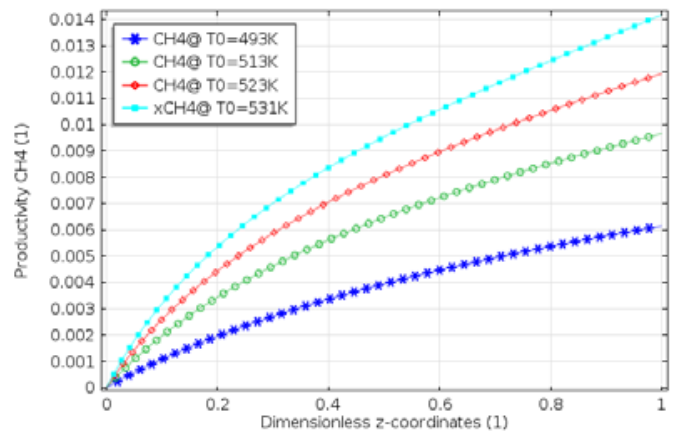

Figure 7: $\mathrm{CH} 4$ productivity with PCM-temperatureregulation $(\mathrm{w}=0.5)$

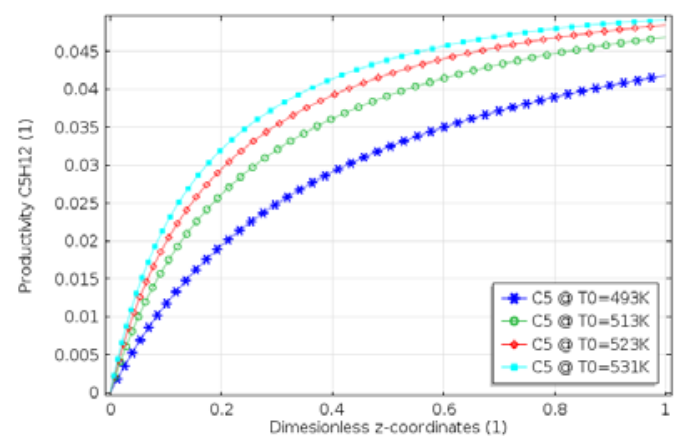

Figure 8: C5 productivity with PCM-temperature regulation $(\mathrm{w}=0.5)$

cooling fluid were assumed to be the same (T0). It was also assumed that the cooling fluid was circulated at a rate fast enough to maintain isothermal conditions at the tube wall and that the direction of flow (co-, cross or countercurrent) was immaterial. Without any input from the PCM, the result is the profile in Figure 3 with an accentuated maximum temperature near the reactor inlet. Increasing the inlet temperature generally exacerbates the maximum temperature. It also influences the productivity of the more valuable $\mathrm{C} 5$ and less desirable $\mathrm{CH}_{4}$ - see Figures 4 and 5. It would seem at first from Figure 5, that increasing T0 monotonically, correspondingly accelerates the kinetics and increases the C5 productivity indefinitely, however, at $523 \mathrm{~K}$ and $531 \mathrm{~K}$, the productivity of $\mathrm{C} 5$ plateaus at $4.5 \%$. Methane production however increases exponentially with temperature. In fact, left to the thermodynamics of the process, the limiting products will be carbon and $\mathrm{CH}_{4}[3,8-12]$.

This corresponding change in the maximum temperature and yield observed also known as parametric sensitivity is due to the exponential dependency of the rate of reaction on 
temperature increase (Arrhenius equation). The rate of heat removal by the jacket cooling fluid at constant cooling temperature however increases linearly (Newton's law of cooling). It follows that, when an upper temperature threshold is exceeded, the heat released will excel that removed, the reaction will "ignite" and proceed at a tremendous rate. On the other hand, if a lower temperature limit is reached, the heat removal overtakes evolution and the reaction is extinguished altogether. These two scenarios depict the extremes of multiple stationary states that could be brought about by thermal instabilities. [7, 13-14].

There is however a noticeable change in the axial temperature profile (Figure 6), with the introduction of the PCM. Due to their microsize and proximity to the catalyst, the PCM is able to provide excellent temperature control within $1{ }^{\circ} \mathrm{C}$. It is also interesting to note that even when the syngas is introduced into the reactor at a temperature greater than the $\mathrm{ptt}$ $(505 \mathrm{~K})$, the PCM still exercises a measure of control on the bed temperature- a delay in temperature rise is brought about even at $531 \mathrm{~K}$, well above its ptt (Figure 6). A dip can be seen in the $531 \mathrm{~K}$-curve (Figure 6 ) at $\sim \mathrm{z}=$ 0.65 . At this elevated temperature (above the ptt), it can be expected that the PCM gets spent much quicker and it follows that the plateauprofile cannot be sustained for very long. The fractional mass of solid PCM available to isothermally absorb the progressive enthalpy of reaction is depleted quicker; the result is the point of inflection observed more than halfway through the reactor. Beyond this point, the rest of the profile becomes less stable compared to the previous trend of temperature profiles.

The effect of this temperature control brought about by the PCM on the productivity of $\mathrm{C} 5$ and $\mathrm{CH}_{4}$ is also interesting. Comparing Figures 4 and 7 it can be seen that the methane production has almost been halved in the latter. This is because the temperature modulation brought about by the PCM limits the exponential increase of the reaction rate of the methane reaction. Comparing Figures 5 and 8 also shows approximately a $10 \%$ mark-up in the $\mathrm{C} 5$ productivity. It is pertinent to note that this mark-up is achieved without large temperature spikes. This could potentially open up the possibility of the catalyst activity being increased, e.g. by the addition of oxides of alkali and some transition metals (e.g. $\mathrm{K}_{2} \mathrm{O}$, $\mathrm{CuO}$, etc.). Thus, increasing the conversion per pass with reduced heat transport penalties and possibly reducing associated recycling costs.

\section{Conclusions:}

A 2-D pseudo-homogeneous, steady-state model for low temperature Fischer-Tropsch reaction in a fixed bed reactor was presented. The effect of temperature regulation using PCM on the selectivity of products was also studied. The results from the model generally underpin the thermodynamic predictions of the FT reaction, that is, a good handle on temperature control could shift the equilibrium towards the selectivity of the more desirable products. The delay in temperature rise due to phase transition by the PCM generally keeps the reaction bed in a narrow temperature window and by extension maintains the desirable selectivity window. The potential control capabilities of the PCM can be seen: by optimising the PCM content, the temperature rise in the reactor and the exponential increment of the reaction rate can be controlled and maintained within a chosen range. The PCM characteristics (e.g. mass fraction, size, melt-time, etc.) are potential distributed control tuning parameters. Catalyst supports could also be impregnated with PCM in future as a temperature control buffer in addition to principal supervisory control mechanisms.

\section{Nomenclature}

\section{Roman Letters}

$A_{p, e x}=$ external surface area of catalyst particle $\left[\mathrm{m}^{2}\right]$

$c=$ concentration $\left[\mathrm{mol} / \mathrm{m}^{3}\right]$

$C_{p}=$ molar heat capacity $[\mathrm{J} / \mathrm{mol} . \mathrm{K}]$

$D_{e r}=$ effective radial mass diffusion 
coefficient $\left[\mathrm{m}^{2} / \mathrm{s}\right]$

$D_{p}=$ particle diameter [m]

$d=$ tube internal diameter

$G=$ superficial mass velocity $\left[\mathrm{kg} / \mathrm{m}^{2} . \mathrm{s}\right]$

$G H S V=$ Gas hour space velocity

$\left[\mathrm{Nm}^{3} \mathrm{~kg}_{\text {cat }}{ }^{-1} \mathrm{~h}^{-1}\right]$

$k_{m}=$ rate constant for pseudo-first order

reaction $\left[\mathrm{m}^{3} /(\mathrm{kg} . \mathrm{s})\right]$

$k_{m, \text { eff }}=$ effective reaction rate constant

[mol/(kg.s)]

$M_{j}=$ Molar mass of species j $[\mathrm{kg} / \mathrm{mol}]$

$m_{\text {cat }}=$ mass of catalyst $[\mathrm{kg}]$

$n=$ molar flow rate $[\mathrm{mol} / \mathrm{s}]$

$P=$ total pressure $[\mathrm{Pa}]$

$R=$ universal gas constant $\left[\mathrm{J} \cdot \mathrm{mol}^{-1} \mathrm{~K}^{-1}\right]$

$R=$ internal radius of tube

$r=$ radial direction [dimensionless]

$r_{m}=$ reaction rate per unit mass of catalyst

[mol/(kg.s)]

$r_{m, e f f}=$ effective reaction rate per mass of

catalyst [mol/(kg.s)]

$S=$ selectivity [dimensionless]

$S_{o}=$ selectivity of olefins [dimensionless]

$S_{p}=$ selectivity of paraffin [dimensionless]

$t=$ time $[\mathrm{s}]$

$T=$ temperature $[\mathrm{K}]$

T0 $=$ inlet temperature $[\mathrm{K}]$

$T_{w}=$ wall temperature $[\mathrm{K}]$

$u_{s}=$ superficial gas velocity $[\mathrm{m} / \mathrm{s}]$

$U_{\text {wall }}=$ thermal transmittance $\left[\mathrm{W} /\left(\mathrm{m}^{2} \mathrm{~K}\right)\right]$

$V_{p}=$ particle volume $\left[\mathrm{m}^{3}\right]$

$w_{j}=$ mass fraction of species $\mathrm{j}$ [dimensionless]

$z=$ axial position in the tube [m]

\section{Greek Letters}

$\alpha=$ carbon chain growth probability factor

[dimensionless]

$\Delta_{\text {fus }} H_{P C M}=$ enthalpy of fusion of PCM [J/mol]

$\Delta_{\mathrm{R}} H_{298}^{\theta}=$ enthalpy of reaction [J/mol]

$\varepsilon=$ void fraction of catalyst bed

[dimensionless]

$\varphi=$ liquid fraction in melt region

[dimensionless]

$\kappa=$ thermal conductivity $[\mathrm{W} /(\mathrm{m} . \mathrm{K})]$

$\mu=$ fluid dynamic viscosity [Pa.s]

$\rho=$ density $\left[\mathrm{kg} / \mathrm{m}^{3}\right]$

$\omega=$ ratio of mass of PCM to mass of catalyst

[dimensionless]
Sub-scripts

$\mathrm{b}=$ bulk

cat $=$ catalyst

cool $=$ cooling

$\mathrm{f}=$ pseudo-fluid

FT $=$ Fischer-Tropsch reaction

$\mathrm{g}=$ gas phase

$\mathrm{i}=\mathrm{i}^{\text {th }}$ reaction

int $=$ internal

$\mathrm{j}=$ species $\mathrm{j}$

$1=$ liquid phase

$\mathrm{M}=$ methane formation reaction

$\mathrm{s}=$ solid

WGS = water gas shift reaction

\section{References}

[1] Jess, A., Kern, C. Modelling of Multitubular Reactors for Fischer-Tropsch Synthesis. Chemical Engineering Technology 32 (8), pp.1164-1175; 2009

[2] Rafiq, M.H., Jakobsen, H.A., Schmid, R., Hustad, J.E., Experimental studies and modelling of a fixed bed reactor for FischerTropsch synthesis using bio-syngas. Fuel Processing Technology 92, pp. 893-907; 2011

[3] Pratt, J.W., A Fischer-Tropsch Synthesis Reactor model Framework for Liquid biofuels production. Sandia National Laboratories, California, September 2012

[4] Pattison, R.C., Baldea, M. A Thermal Flywheel Approach to Distributed Temperature Control in Micro-Channel Reactors; AIChE J., Vol 00, No. 00, January 2013.

[5] De Deugd R.J., Fischer Tropsch Synthesis Revisited: Efficiency and Selectivity Benefits from Imposing Temporal and/or Spatial Structure in the Reactor. Technische Universiteit Delft, Netherlands, January 2004

[6] Zhu X., Lu, X., Liu, X., Hilderbrandt D., Glasser D., Study of Radial Heat Transfer in a Tubular Fischer-Tropsch Synthesis Reactor. 
Ind. Eng. Chem. 10682-10688; 2010

[7] Eigenberger, G. Institut für Chemische Verfahrenstechnik, Universität Stuttgart, Stuttgart, Fixed Bed Reactors Ullman's Encyclopaedia of Industrial Chemistry, Vol B4. 199-238; 1992.

[8] Dry, M.E., The Fischer-Tropsch ProcessCommercial Aspects. Catalysis Today vol.6 Issue 3, pp.183-206; 1990

[9] Espinoza, R.L., Stynberg, A.P., Jager, B., Vosloo, A.C., Low Temperature FischerTropsch Synthesis from a Sasol Perspective. Applied Catalysis 186, pp 13-26; 1999.

[10] Dry, M.E. The Fischer-Tropsch Process: 1950-2000. Catalysis Today 71, pp. 227-241; 2002

[11] Jager B., Development of Fischer Tropsch Reactors, Sasol Technologies at AIChE Spring Meeting, New Orleans; 1 April 2003.

[12] Yang J.H., Kim H.K. Chun D.H., Lee H.T., Hong J.C., Jung H., Yang J. Mass transfer limitations on fixed bed reactor for Fischer-Tropsch synthesis, Fuel Process Technology, 91 pp.285-289. 2010.

[13] Hong, Y., Ding S., Wu, W., Hu J., Voevodin A. A., Gschwender L., Snyder E., Chow L., Su M. Enhancing heat capacity of colloidal suspension using nanoscale encapsulated phase change materials for heat transfer. Applied Materials and Interfaces (ACS) Vol. 2 (6), pp.1685-1691; 2010

[14] Zhang, M., Hong, Y., Ding, S, Hu J., Fan, Y., Voevodin, A.A., Su, M. Encapsulated nano-heat sinks for thermal management of heterogeneous chemical reactions. Nanoscale (2) pp 2790-2797; 2010

[15] Yokota T., Murayama M., Howe J.M. Phys. Rev. Lett., 91, 265504; 2003.

[16] Mittal, A., Roy, S., Larachi, F. Modelling of heat uptake and release with embedded phase-change materials in monolithic microfluidised bed reactors. Ind.Eng. Chem. Res. (49), pp. 1086-1097, 2010.

[17] Lamberg, P., Lehtiniemi, R., Henell, A. Numerical and experimental investigation of melting and freezing processes in phase change material storage. International Journal of Thermal Sciences 43, pp. 277-287; 2004

[18] Froment, G. Fixed bed catalytic reactors: current design and status. Industrial and Engineering Chemistry Vol. 59 (2), pp. 18-27; 1967.

[19] Froment G.F., Bischoff, K.B. Chemical Reactor Analysis and design, $2^{\text {nd }}$ Ed., John Wiley and Sons, 1990

[20] Howard, F.R., Fixed bed reactor design and diagnostics: gas phase reactions, Butterworths, 1990.

[21] Richardson J.F., Peacock, G.G., Coulson and Richardson's Chemical Engineering Vol. $3,3^{\text {rd }} \mathrm{Ed} ; 1994$ 